Revista Iberoamericana, Vol. LXXI, Núm. 211, Abril-Junio 2005, 575-589

\title{
TECNOLOGÍAS DE LA REPRESENTACIÓN EN EL HABLADOR, DE MARIO VARGAS LLOSA
}

POR

\author{
Sergio R. Franco \\ University of Pittsburgh
}

El hablador (1987) es, sin duda, la novela de Mario Vargas Llosa que ha concitado la mayor atención de la crítica especializada en la última década. Esto no ha de sorprender, puesto que se trata de un texto particularmente rico, atravesado por dicotomías que se hallan en el centro de la reflexión del debate contemporáneo en distintas áreas intelectuales del latinoamericanismo tales como oralidad/escritura; audición/lectura; letrado/no letrado; verdad/ficción; comunidad/sujeto; comunidad/nación; hegemonía/margen; tradición/ modernidad; normalidad/anormalidad. No obstante, los diversos investigadores que se han acercado a esta obra han obliterado el nivel de las tecnologías de la representación, ${ }^{1}$ aspecto que considero crucial dentro de la propuesta global de su sentido y a cuyo examen se dedica el presente artículo.

Hablo de “tecnologías de la representación” para referirme a los procedimientos técnicos y narratológicos mediante los cuales se elaboran las representaciones literarias, pero no por ello dejo de pensar las tecnologías como operaciones mediante las cuales los individuos manipulan sus propios cuerpos (Foucault, Tecnologías del yo), así como procesos a través de los cuales se da forma concreta a conceptos ideológicos (O’Sullivan, 307). Sostengo que una representación ${ }^{2}$ (del latín representare, "poner delante”) es una operación paradójica por la que se hace nuevamente presente algo (re-presentar) a través de un sustituto fabricado expresamente para ello, o dislocado de sus funciones primigenias, para que cumpla la función de denotar al primero, independientemente de que exista entre

\footnotetext{
${ }^{1}$ En lo que atañe a la crítica dedicada a El hablador afín a mi perspectiva, debo mencionar a Lucille Kerr, quien adelanta agudos comentarios sobre "la muerte del autor como fotógrafo" (134-59).

${ }^{2}$ W.J. Mitchell propone entender la representación mediante un esquema cuatripartito en el que un objeto representa a otro. Ese objeto que representa es elaborado por alguien para efecto de que lo contemple otro individuo, y, si bien significa algo diferente a lo que es, posibilita a la vez que obstaculiza el contacto directo entre representante y representado (12-13). Tengo una objeción a este planteamiento: la idea de que una representación se dirige solamente a las personas es errónea, aun cuando no lo parezca. Consideremos, si no, el caso de un espantapájaros, representación elaborada para «engañar» aves antes que individuos. De otro lado, la asimilación de la representación al signo que efectúa Mitchell (y él mismo nos recuerda, siguiendo a Charles S. Pierce, que lo signos pueden ser íconos, índices y símbolos), incluso en una definición atómica, no ilumina esta intrincada cuestión.
} 
el elemento representado y el elemento representante semejanza alguna. Ahora bien, el elemento representado no existe como algo puro, aislado de sus propiedades, sino que está construido perceptualmente: no se olvide que toda percepción es cultural. La elaboración del elemento representante dependerá, a su vez, de que satisfaga ciertas convenciones de representación. Estas convenciones implican seleccionar determinados “rasgos” de aquellos que atribuimos al objeto a representar así como actualizar determinados códigos o sistemas de significación social. Ahora, si toda representación es un sutituto, yo considero que ésta se halla delimitada, fundamentalmente, por: a) los sistemas ético-ideológicos, que determinan lo que en una sociedad, en un momento dado, está permitido representar, y b) las posibilidades técnicas alcanzadas por el medio que se emplea para efecto de la representación.

El discurso de El hablador (1987) se desencadena de un modo sencillísimo: mientras se halla en Florencia, Italia, un escritor peruano (a quien denominaré “el novelista”) que puede confundirse con el Vargas Llosa real efectivo, asiste a una exposición fotográfica cuyo tema es la Amazonía. Entre las diversas imágenes cree reconocer, bajo la figura de un narrador oral, a un amigo de épocas universitarias misteriosamente desparecido. El viejo condiscípulo, Saúl Zuratas, un peruano de origen judío centroeuropeo, estaba marcado por un inmenso lunar morado que le cubría la mitad del rostro, por lo que la gente lo apelaba "Mascarita”. Zuratas parecía destinado a convertirse en una figura académica de primer orden en el campo de la etnología; no obstante, conforme avanzaba el reconocimiento académico hacia su tarea, iba experimentando cada vez más dudas respecto al talante mismo de la empresa cultural en que se veía inmerso. El conflicto interior llega a un punto tal que Zuratas reniega de su profesión, a la que entiende como un vía para la aculturación de los indígenas, su consiguiente explotación y la desintegración de su etnicidad. Así mismo, a juzgar por la fotografía que desencadena el proceso memorioso en el novelista, Zuratas podría haberse integrado a la etnia amazónica machiguenga, con la que el propio novelista entró en contacto durante su juventud. ${ }^{3}$

Son tres las instancias narrativas que posee esta novela. La primera es el relato-marco (capítulos I y VIII) que se desarrolla en Florencia, donde el novelista se encuentra de visita. La segunda nos la proporciona una analepsis subdividida en tres partes, destinada a recuperar el pasado del novelista (capítulos II, IV y VI). En esta sección se producen decisivos contrapuntos entre lo que se refiere que ocurrió y lo que acontece en el presente desde el cual se evoca. Por último, contamos con una temporalidad aparentemente mítica, que es la recreada en los relatos entregados por una voz cuya dicción sugiere un hablador machiguenga (capítulos III, V y VII). Así, pues, la novela se construye mediante una arquitectura simple y alternada, a la vez que eficaz y rigurosa, ya que solamente contamos con dos voces: la del novelista y la del hablador. Se refuerza, de este modo, el diseño de dos trayectorias disímiles. De un lado, el novelista plenamente identificado con la cultura occidental (Sommer, 93-95) que intenta fabricar, a partir de los monumentos de Europa, la imagen de un espacio seguro y consolador: la armonía de la pintura renacentista como

\footnotetext{
${ }^{3}$ Para una valiosa aproximación entre el novelista del El hablador y el sujeto de la escritura en el texto clásico de la antropología Tristes Tropiques (1955), de Claude Lévi-Strauss, véase Sara CastroKlaren. "Monuments and Scribes: El hablador Addresses Ethnography”, 44-5.
} 
paliativo para los dolores que le inflige la realidad peruana. De otro, Saúl Zuratas, el peruano culturalmente escindido que no quiso ir a Europa -por más que a ello lo instó su amigo- y que, tal vez, encontró su propio refugio entre los indígenas amazónicos: un espacio donde la marca de su rostro ya no ha de ser un estigma.

Hay en El hablador otra divergencia concomitante: la que opone el arte de la novela y la antigua narración oral. En efecto, el personaje "Vargas Llosa” asume una saga creativa que el lector es inducido a identificar con la que le corresponde al autor real. Por su parte, Zuratas -si realmente se convirtió en un hablador- deviene el nexo viviente de una comunidad desperdigada, y el guardián de su pasado:

El nombre los definía. Hablaban. Sus bocas eran los vínculos aglutinantes de esa sociedad a la que la lucha por la supervivencia había obligado a resquebrajarse y desperdigarse a los cuatro vientos. Gracias a los habladores, los padres sabían de los hijos, los hermanos de las hermanas, y gracias a ellos se enteraban de las muertes, nacimientos y demás sucesos de la tribu. (90-91)

En su excelente ensayo de 1933, “Der Erzähle”, Walter Banjamin establecía que la narración tradicional suponía la comunicabilidad de una experiencia fundada en una sabiduría y una herencia cultural comunitarias. La modernidad, cuyo punto neurálgico es alegorizado por Benjamin en el trauma provocado por la inenarrabilidad de la Primera Guerra Mundial, altera por completo el arte de la narración y ubica al individuo ante la necesidad de redefinir su relación con el relato, lo comunitario, la información, la memoria y la muerte. Si el relato del narrador oral reforzaba la socialidad del grupo, la modernidad contempló el triunfo de la novela, que se produce y consume solitariamente, y cuyo basamento consiste en la subjetividad, el individualismo burgués y el idealismo cartesiano (Benjamin, "El narrador”).

El novelista de El hablador viaja hasta Florencia con la intención de olvidar su país pero termina contemplando las fotografías que el italiano Gabriele Malfatti, poco antes de morir, realizó en la selva peruana. En unas cuartillas que acompañan a la exposición, se indica que el fotógrafo intentó captar la cotidianeidad de una tribu amazónica "sin demagogia ni esteticismo” (8), lo que, de acuerdo al novelista, consiguen las imágenes. No es esto, sin embargo, lo que desconcierta a este último sino que Malfatti logró acceder a un ritual secreto tan celosamente guardado que incluso él, a pesar de muchos esfuerzos y pesquisas para indagar acerca de los habladores, jamás pudo atestiguar. ¿Cómo entender esta disparidad de logros? Resulta tentador pensar que ella se explica porque el fotógrafo se interesa por su objeto tal y como éste es, colocándose, al menos por un breve lapso, a favor del status quo (Sontag, 12), lo que no se puede decir del novelista, preocupado por incorporar la etnia machiguenga a la modernidad (72). De ser así, podríamos casi hablar de justicia poética pero, por supuesto, las cosas son más complicadas. El novelista conjetura que el acelerado proceso de transformación social en la zona del Alto Urubamba ha provocado una aculturación de los indígenas, con la consiguiente pérdida de autenticidad de sus rituales, degenerados en meras pantomimas para turistas (228). Es posible. En todo caso, la operación del fotógrafo tampoco es objetiva ni carece de violencia (Sontag, 7), la violencia esencialmente "pornográfica" que existe en lo visual, en su aprehender el mundo como si contemplara un cuerpo desnudo (Jameson, Signatures of the Visible 1-6). 
Pero no es sólo que las fotos remitan al novelista a su propio pasado, a su experiencia en la selva peruana, o que inserten la pieza final en el rompecabezas que es la vida de Zuratas. La verdadera contraposición apunta hacia otro lado: el novelista, durante mucho tiempo, había intentado representar, mediante su arte, a los habladores machiguenga:

\begin{abstract}
¿Por qué había sido incapaz, en el curso de todos aquellos años, de escribir mi relato sobre los habladores? La respuesta que me solía dar, vez que despachaba a la basura el manuscrito a medio hacer de aquella huidiza historia, era la dificultad que significaba inventar, en español y dentro de esquemas intelectuales lógicos, una forma literaria que verosímilmente sugiriese la manera de contar de un hombre primitivo, de mentalidad mágico-religiosa. Todos mis intentos culminaban siempre en un estilo que me parecía tan obviamente fraudulento, tan poco persuasivo como aquellos en los que, en el siglo XviII, cuando se puso de moda en Europa el "buen salvaje", hacían hablar a sus personajes exóticos los filósofos y novelistas de la ilustración. (152)
\end{abstract}

El novelista siente que ahí donde sus escritos fallan, la fotografía se impone con su aplastante inmediatez. Capturado por las imágenes, acepta la fotografía como un "análogo mecánico de lo real” (Barthes, "El mensaje...” 14), como connatural a su referente (Barthes, La cámara lúcida 32). ${ }^{4}$ Por lo tanto, jamás se interroga por la naturaleza misma de la representacion y sus convenciones, pues el arte de la fotografía no proporciona una imagen en tiempo real o virtual sino una imagen analógica; el aparato fotográfico mismo ha sido construido para funcionar de acuerdo a un régimen escópico muy preciso, elaborado por el Quattrocento italiano. La fotografía hereda de la pintura la perspectiva linear, la reducción del espacio pluridimensional a un espacio bidimensional, el privilegio de la verticalidad -que la pintura moderna abandona- y el eje cultural de presencia/ ausencia en cuanto a los rasgos convencionales mediante los cuales se reconocen y representan los objetos (Aumont, 31-37). Es muy característico que el novelista naturalice las fotografías mediante su descripción, lo que les otorga una configuración distinta al atribuirles predicados ajenos a ella:

La fotografía que esperaba desde que entré a la galería, apareció entre las últimas. Al primer golpe de vista se advertía que aquella comunidad de hombres y mujeres sentados en círculo, a la manera amazónica -parecida a la oriental: las piernas en cruz, flexionadas horizontalmente, el tronco muy erguido-, y bañados por una luz que comenzaba a ceder, de crepúsculo tornándose noche, estaba hipnóticamente concentrada. Su inmovilidad era absoluta. Todas las caras se orientaban, como los radios de una circunferencia, hacia el punto central, una silueta masculina que, de pie en el corazón de la ronda de machiguengas imantados por ella, hablaba, moviendo los brazos. (9-10, énfasis mío)

\footnotetext{
${ }^{4}$ Linda Hutcheon ha mencionado el carácter semióticamente híbrido de la fotografía: "In Pierce’s terms, it is both indexical (its representation is based on some physical connection) and iconic (it is a representation of likeness) in its relation to the real (...) the addition of language is the addition of the symbolic to the indexical and the iconic. The process of 'reading' the conventions of both the verbal and the visual can now be seen as related, though different: both involve hermeneutic work by the viewer, but this work includes the interpretation of three types of signs, as well as their combination" (130-1). Para otro valioso examen remito a Clive Scott: 17-45.
} 
Jean Baudrillard se ha referido al silencio de la fotografía -sobre lo que volveré más adelante- como una de las más valiosas y originales cualidades de este medio, pues, a diferencia de otras tecnologías que con dificultad lo procuran, ella fácilmente elude lo discursivo mediante la inmovilización fenoménica de una apariencia que se emancipa del objeto real (28-31). Con todo, debemos recordar que la identidad de la fotografía depende de las instituciones que determinan su uso (Tagg, 63). Para el novelista, la fotografía funciona como herramienta de una pesquisa: ${ }^{5}$

Cierto que la figura de pie denota en la cara una sombra más intensa -en el lado derecho, donde él tenía el lunar-, que podría ser clave para identificarlo (...) Quizá la pista más sólida sea la conformación de la silueta. Aunque esté lejos, no hay duda: ésa no es la arquitectura típica de un indio de la selva, hombre por lo general bajo, de piernas cortas y ovaladas y ancha caja torácica. Quien está hablando tiene un cuerpo alargado y juraría que una piel -está desnudo de la cintura para arriba- mucho más clara que la de su auditorio. Pero sus pelos muestran, eso sí, el corte circular, como capucha medieval, de un machiguenga. (230)

El novelista intenta animar la foto imaginando para ella la voz y el movimiento, lo que nos lleva directamente a lo audiovisual, tecnología que también lo exalta y turba. Prueba suerte con un programa televisivo denominado La Torre de Babel, el cual lo obliga a diversos viajes en busca de material. De hecho, la hipótesis de que Saúl Zuratas haya devenido un hablador machiguenga se le ocurre tras conversar, por segunda vez en su vida, con los Schneil, una pareja de lingüistas estadounidenses al servicio del Instituto Lingüístico de Verano, y a efecto de elaborar una de sus emisiones semanales. Pero, ¿cuáles fueron las razones que lo llevaron a la televisión?

(...) la necesidad de elevar el nivel de los programas, que, en los doce años precedentes, mientras la televisión permanecía estatizada por la dictadura militar, habían tocado fondo en lo que concierne a estupidez y vulgaridad; lo excitante de experimentar con un medio de comunicación que, en un país como el Perú, era el único capaz de llegar simultáneamente a los públicos más diversos; y un buen salario. (141)

El talante ilustrado y redentor con que se asume el medio importa menos que la fe en que gracias a él se superará la fractura social peruana. Puede parecer paradójico que este designio vaya de la mano con un proyecto de carácter misceláneo como el de su programa. ${ }^{6}$

\footnotetext{
${ }^{5} \mathrm{El}$ auge de la fotografía ocurre durante un período en que se produce el declive de la religión en el imaginario de Occidente, suplantada por la democracia y la ciencia. La fotografía colabora con la segunda y auxilia en el proceso de industrialización, en la vigilancia y el control. Todo esto le otorga un estatuto de verdad pues se le presume como suministradora de documentos objetivos (Tagg; Berger, 53-54).

${ }^{6}$ Aunque no lo diga, este afán inclusivo intenta mantener en equilibrio la "alta” y la "baja” cultura: una visita a Borges alterna con otra a Corín Tellado; se conversa con Omar Torrijos y se dedica tiempo al box panameño; Czeslaw Milosz es entrevistado y, también, el futbolista Zico. Este mismo criterio omniabarcante guía la producción periodística de Mario Vargas Llosa. A ese respecto, véase mi reseña a su libro El lenguaje de la pasión.
} 
Pero la paradoja desaparece cuando recordamos que estamos ante un medio caracterizado por su capacidad para incorporar los materiales más diversos, así como por disolver las jerarquías ilustradas en su ininterrumpido conglomerado de imágenes, las cuales operan ante nosotros como significantes vaciados de referencialidad (Ellis, 122).

La incursión televisiva -que obliga al trabajo colectivo, ajeno a la distintiva soledad creadora del novelista-resultará poco satisfactoria. El producto final muestra imperfecciones en el acabado -aspecto crucial, vale la pena recordarlo, en el arte del Mario Vargas Llosa real efectivo- derivadas de desperfectos técnicos de los instrumentos con que tiene que trabajar:

Cuando, con Lucho y Moshé, hacíamos listas de temas, personas y lugares de los que debería ocuparse La Torre de Babel y planeábamos la manera más agil de presentarlos, todo funcionaba a las mil maravillas. Estábamos llenos de ideas y con muchas ganas de descubrir las posibilidades creativas del más popular medio de comunicación de nuestro tiempo.

Lo que descubrimos fueron, más bien, las servidumbres del subdesarrollo, el modo sutil con que desnaturaliza las mejores intenciones y frustra los más arduos esfuerzos. (142)

El “ya se jodió” con que el camarógrafo Alejandro Pérez invariablemente anuncia la falla de alguno de los aparatos nos remite, de algún modo, a la desconcertada pregunta que Santiago Zavala se formula en Conversación en la Catedral (1969) -y que no suele citarse correctamente- “¿en qué momento se había jodido el Perú?” (13). ${ }^{7}$ Se ha solido interpretar esta pregunta desde una perspectiva que combina lo existencial con lo social, pues el fracaso del personaje es también el fracaso peruano. Pues bien, desde la perspectiva de El hablador, “joderse” tiene que ver con la constatación de un modernización defectuosa:

¿Cuántas veces se “jodió” la grabadora, la cinta, el reflector, la batería, el monitor? Todo podía "joderse" innumerables veces: era una propiedad de las cosas con las que trabajábamos, acaso la única a la que todos mostraron una fidelidad perruna. (144)

Estos problemas imponen al novelista una conducta "picaresca” a fin de encontrar soluciones y salvar la distancia que media entre "la teoría y la práctica, las disposiciones y los hechos" ("emblema” del subdesarrollo, 146):

\footnotetext{
${ }^{7}$ Vale decir: “¿en qué momento se ha jodido el Perú?”, pues el narrador heterodiegético reformula, mediante el discurso indirecto libre, lo que el personaje piensa. El discurso indirecto libre es una forma híbrida que gramaticalmente pertenece al narrador pero desde la perspectiva del sentido pertenece al personaje. Es crucial la modalidad apreciativa que se manifiesta en sus entonaciones, donde resuenan ecos de una voz distinta a la que narra. Se le considera como una manifestación exclusiva del lenguaje escrito (Beltrán Almería; Voloshinov, 195-209). Hamburger lo caracteriza concisamente: el discurso indirecto libre reproduce en tercera persona una corriente de conciencia informulada (Hamburger, 65-69). El enfoque teórico de mayor alcance en la actualidad se encuentra, me parece, en Fludernik. El lector que desee conocer la reflexión del propio Mario Vargas Llosa sobre el tema deberá consultar La orgía perpetua. Flaubert y Madame Bovary (237-41).
} 
Aprendimos rápidamente, claro está, las trampas, astucias, pillerías o gracias de que había que valerse para lograr, nada que fuera un privilegio, sino, apenas, hacer con un mínimo de decoro aquello por lo cual nos pagaban. Todas eran tretas asequibles, pero todas tenían el defecto de privarnos de un tiempo precioso que hubiéramos debido dedicar a lo puramente creativo. Después de haber pasado por aquella experiencia, cuando me ocurre, alguna vez, ver en la televisión un programa bien grabado y editado, ágil, original, mi admiración no tiene límites. Porque sé que, detrás de eso, hay mucho más que empeño y talento: hechicería, magia. (146)

No hay que sorprenderse de que se aluda a la magia, pues la diferencia entre ésta y la técnica consiste en una variable histórica. Al mismo tiempo, el desencanto que proviene de la incapacidad para producir representaciones que satisfagan los estándares de calidad del mundo en que se mueve debe relacionarse con una ironización del proyecto que anheló construir una integración nacional con medios inapropiados. Que el programa se denomine La Torre de $\mathrm{Babel}^{8}$ pregona claramente no sólo la confusión derivada de la multiplicidad irreductible de las lenguas que tradicionalmente se atribuye al mito, sino la imposibilidad de concluir una empresa totalizante (Derrida, “The Tower of Babel” 209-248).

La fotografía y la televisión generan insatisfacciones al novelista; la literatura le sirve para conseguir una monumentalización estética de lo caótico y la pintura le brinda sosiego. Lo que hay de por medio es una mezcla de desconfianza y fascinación por los medios posauráticos, emblematizados en las perturbadoras fotografías de Malfatti o en la frustración de La Torre de Babel. La adhesión a la escritura va de la mano con el rechazo a tecnemas más recientes y se explica del siguiente modo: existe un continuum en las formas del relato que va de la narrativa oral a la escrita y, de ésta, a la audiovisual. De lo que se trata es de un perfeccionamiento técnico análogo al que supuso el reemplazo de los animales de tiro por el tractor en la agricultura (Jameson, “De la sustitución...” 117-132). En tal sentido, creo apropiado interpretar que la oralidad del narrador puede ser homenajeada en El hablador porque aparece como superada o arcaica y, a fin de cuentas, no inspira incomodidad, lo que sí ocurre con las nuevas tecnologías que, de facto, obligan a las previas a redefinirse. El hablador hipnotiza a su auditorio (172), pero quien asuma expresarse a través de la televisión encara inevitablemente la amenza del zapping. Más aún, la televisión -que proporciona información descontextualizada, que establece una relación monológica con su audiencia, que genera nuevas modalidades de archivo, que construye su propia referencialidad semiológica, que se sustrae a los imperativos instrumentales de la comunicación- disuelve al sujeto autónomo, masculino y burgués configurado desde la modernidad como la piedra de toque de la racionalidad de Occidente. Esto es así porque los lenguajes mediáticos minan las bases de la referencialidad discursiva; es decir, aquéllas que sostienen al ego racional (Derrida y Stiegler; Poster, 46). ${ }^{9}$

\footnotetext{
${ }^{8}$ No faltará quien indique que en el mundo real efectivo el novelista Mario Vargas Llosa condujo un programa de televisión llamado La torre de Babel. Ello no invalida la connotación que ofrece el nombre del programa dentro de la novela. Más aún, la mera selección de ese dato, de todo el conjunto de los muchos que ofrece al autor real su propia vida, refrenda su importancia simbólica.

${ }^{9}$ Los nuevos medios cuestionan la distinción tradicional entre la escritura y la oralidad. La invención de la escritura implicó la posibilidad de una comunicación a distancia, generó cambios en la
} 
El hablador añade una nueva y rica variación al tópico vargasllosiano de la reflexión sobre las tecnologías de la representación, ostensible ya desde La ciudad y los perros (1963), pero particularmente intensificado en textos como La tía Julia y el escribidor (1977) o Historia de Mayta (1984). No deja de ser sintomático que todos estos textos, así como el que motiva este trabajo, incorporen lo autobiográfico como una de sus líneas de fuerza, y que los dos más notables a este respecto -La tía Julia y el escribidor, y El hablador- evoquen autobiografías estéticas o autoficciones..$^{10} \mathrm{El}$ texto exhibe una suerte de contradicción entre la celebración de las antiguas tecnologías del relato y el anhelo de modernización de la sociedad peruana que podría acarrear la modificación tecnológica de los relatos, así como la reubicación de la actividad letrada. Ante este predicamento, la novela pone en escena intentos de apropiación discursiva de distintas técnicas que resemiotiza desde su propia esfera. A la plenitud icónica de las fotografias, la escritura opone la minuciosidad descriptiva de las mismas; a la oralidad del narrador, el pastiche ${ }^{11}$ de su oralidad "trucada” (Klüppelholz, 2003). Esto implica que, en rigor, la novela no intenta transgredir los propios límites de su elaboración cultural, puesto que la creación de "Mascarita" proyecta lo mismo sobre lo otro, aspecto que verificamos a nivel de la historia. Así, el novelista y Saúl Zuratas resultan muy similares entre sí: ambos aparecen disconformes con la cultura propia; ambos estudian derecho pero poseen otra pasión; ambos parecen entender la otredad indígena bajo una perspectiva "colonial”, de ahí la preocupación por "fijar" la identidad machiguenga (Zuratas) o considerar que ella no existe más en cuanto se transforma $(72,97,228-229) .{ }^{12}$ Cuando Zuratas se convierte en

apropiación semiótica del mundo (en el volumen de la información a conservar, muy limitado en la memoria oral) y abrió las puertas a una era de creación individual (Lotman, 217). Las nuevas tecnologías -televisión, telégrafo, teléfono, radio, computadoras, satélite, videograbación- socavan el criterio de distancia/lejanía que se hereda de la comunicación cara a cara: si bien las distancias se incrementan, las palabras no pueden ser ubicadas con precisión en un eje espacio-temporal (Poster, 84-5).

${ }^{10}$ La autobiografía estética es una elaboración que opera mediante un "ego" perteneciente tanto al autor real como al personaje del texto, lo que causa que las interrelaciones entre el autor real y el personaje sean notablemente más complejas y ambiguas que las que se dan en una autobiografía “tradicional”. En este caso, el "pacto autobiográfico" implícito se puede presuponer en este tipo de textos de modo laxo y sobreentendido, pero no parece tan fácilmente verificable. Del mismo modo, la noción de sinceridad, que se apoya en una idea de la verdad como "correspondencia”, cede lugar a la emergencia de una verdad simbólica o emblemática (cf. Nalbantiam, 43-61). La autoficción consiste en un discurso recuperado para la novela desde el paratexto aun si el autor, el narrador y el personaje comparten la misma identidad nominal (Dubrovsky, 61-79).

${ }^{11}$ Uso la categoría conforme la definición de Fredric Jameson: "Pastiche is, like parody, the imitation of a peculiar or unique, idiosyncratic style, the wearing of a linguistic mask, speech in a dead language. But is a neutral practice of such mimicry, without any of parody's ulterior motives, amputated of the satiric impulse, devoid of laughter and of any conviction that alongside the abnormal tongue you have momentarily borrowed, some healthy linguistic normality still exists. Pastiche is thus blank parody, a statue with blind eyeballs" (Jameson, "Posmodernism..." 17).

${ }^{12}$ Homi Bhabha señala lo siguiente: "An important feature of colonial discourse is its dependence on the concept of 'fixity' in the ideological construction of otherness. Fixity, as the sign of cultural/ historical/racial difference in the discourse of colonialism, is a paradoxical mode of representation: it connotes rigidity and an unchanging order as well as disorder, degeneracy and demonic repetition" (66). 
hablador de los machiguengas, si tal es el caso, ¿no está ejerciendo dentro de esa sociedad una función que duplica la del novelista?, ¿no se está convirtiendo en un letrado de otro tipo pero letrado al fin?, ¿no se apropia de un capital simbólico, al que extrapola relatos -los Evangelios, Die Verwandlung, de Franz Kafka-que provienen de distintas tradiciones culturales?, ¿y no entra esto en contradicción con la crítica que él mismo dirige a los miembros del Instituto Lingüístico de Verano de incrustarse dentro de las culturas amazónicas para destruirlas desde dentro? (94-95). La operación del hablador/Zuratas adultera la cultura machiguenga y contribuye subrepticiamente a incrementar la difusión de la palabra occidental en la selva (Acosta Cruz, 139-41; Culler, 32; Irvine, 471).

Saúl Zuratas no es el hablador más que en la imaginación del novelista que aparece en El hablador. ${ }^{13}$ En efecto, el novelista y el hablador de la novela no son isodiegéticos, no se ubican realmente en una posición simétrica, menos aún dialógica. Es el primero quien relata la historia de Saúl Zuratas, quien decide que el hablador de la fotografía sea él -“pues, objetivamente, no tengo manera de saberlo” (230)-, y quien desea reconocer en el bulto que hay sobre el hombro izquierdo del hablador que ve en la fotografía a un loro, del cual hará compañero y tótem del narrador (230). En un pasaje revelador del capítulo IV, el novelista menciona su propia praxis de escritor en Florencia, dedicado no tanto a leer a Dante y Maquiavelo, o a contemplar arte renacentista, como a "entretejer los recuerdos y fantasías de esta historia” (88). Que el hablador machiguenga narre hacia el final del capítulo séptimo la historia de un loro que adopta y bautiza con el nombre de "Mascarita" (224) confirma que los relatos atribuidos al hablador, y el personaje mismo del hablador/Zuratas son creaciones del novelista. Los capítulos III, V y VII constituyen otros tantos pastiches de relatos orales y el hablador machiguenga no funciona como un genuino Otro a la cultura occidental ${ }^{14}$ (Booker, 132). De la misma manera, el propio Saúl Zuratas tampoco es un genuino judío, ya que su madre fue una “criollita”de Talara (13),

\footnotetext{
${ }^{13}$ Después de consultar una extensa bibliografía sobre los machiguenga, Benedict Anderson indica que la figura del hablador o narrador oral no existe en esa cultura. Por lo tanto, se trata de una plena creación autorial (Anderson, 350).

${ }^{14}$ Encuentro que la voz que enuncia los capitulos III, V, VII no pasa de una ventriloquia que dista mucho de ser convincente y representa un retroceso dentro de una tradición, la peruana, donde hace mucho se resolvió el problema de formular verosímilmente en español la voz de indígenas que se expresan en su propio idioma. Suscribo la opinión de Doris Sommer, quien, apoyándose en un parecer de José Antonio Mazzotti, detecta en el español de esos segmentos trazas de influjo quechua (Sommer, 97), lo que ameritaría una crítica de la "realización artística de tales capítulos y su falla para imaginar un lenguaje plausible de la otredad”, como observar Jonathan Culler (Culler, 34). Este, sin embargo, se ampara en una opinión de Efrain Kristal - y en otros críticos cuyos nombres no menciona- para extender un juicio laudatorio a ese respecto y declarar que la novela logra inventar audazmente (“boldly”) el lenguaje que al novelista del texto le resulta imposible conseguir (Culler, 31). Sara Castro-Klarén halla verosímil la voz del hablador pero la relaciona con la exploración lingüística de José María Arguedas ( 222), lo que nos devuelve al parecer de Sommer. Decididamente, Emil Volek proclama el discurso del hablador machiguenga una 'magistral creación artística desde adentro y como para un público indígena auténtico” forjado a base de algunos rasgos dialectales del "español de la Amazonía e indígena en general" entre los que sobresalen el gerundio y el dialogismo (36-46). Benedict Anderson, por su parte, califica de "persusiva” esa voz aunque no deja de vincularla al pastiche (355). Como se ve, el tema está abierto a la polémica.
} 
y conforme la Halacha, o ley judía, es judío el hijo de una mujer judía o quien se convierte al judaismo (Fackenheim, 47). El apelativo "Mascarita" - que esconde un esencialismo, pues toda máscara presupone un rostro tras ella, un fondo de "verdad” depositado en lo profundo- alude, sin duda, a la inestabilidad identitaria del personaje. ${ }^{15}$

No parece casual que la mitad del rostro de Saúl Zuratas aparezca cubierta por un inmenso lunar morado ${ }^{16}$ ni que se le tilde de monstruo (16); por el contrario, la marca simboliza su destino dual, híbrido, pues el monstruo es el modelo de la diferencia encarnado (Cohen, 3-25; Foucault, Los anormales 62). Pero hay algo más relevante: la marca que lo deforma lo aproxima a una ilustre figura de de la literatura peruana: Juan de Espinoza Medrano, conocido como “El Lunarejo”. En un discurso titulado“El Lunarejo en Asturias”, pronunciado en la ciudad de Oviedo en noviembre de 1986, con ocasión de recibir el premio Príncipe de Asturias, Mario Vargas Llosa, amén de idealizar la empresa expansionista de Europa, gracias a la que se logró "la inserción de América, por obra de España, en la cultura occidental” (Vargas Llosa, “El Lunarejo...” 356), sostuvo que el Lunarejo sólo podía lograr su independencia integrándose a Occidente, y, por tanto, aunándose al camino que lleva hacia la meta final de la historia a la que se adscribió (359360). Es atractiva esta semejanza entre Saúl Zuratas, presunto hablador, y el Doctor Sublime en una novela que dramatiza la pugna entre las diversas tecnologías de la representación en un momento histórico de clara crisis del sistema literario (Franco), pues tal sistema tuvo su origen en el barroco americano, ligado a la fundación de la ciudad letrada y a su ambivalencia histórica: cómplice del proyecto imperial español y gestor de una conciencia criolla. ${ }^{17}$ Como el Lunarejo, quien en el Apologético en favor de don Luis de Góngora (1662) parte del apodo con que se le estigmatizó para elaborar un emblema que lo reivindica y aproxima al poeta cordobés, equiparado por él, a su vez, a la luna (González Echevarría, 169), el "Zuratas” que el novelista ha gestado a partir del amigo desaparecido superará el hecho de ser entendido como un "monstruo” (16), de que su "humanidad” sea vista como una “máscara”, pero lo hará mediante su afiliación a un grupo percibido como un "horror pintoresco” en la sociedad peruana (30). El hablador, entonces, reactualiza la antigua formación discursiva que entiende la diferencia americana como "monstruosidad" constituida desde la mirada del poder, a fin de legitimar la exclusión y el control del “otro” (Palencia-Roth: 39-62; Zavala: 324-329).

\footnotetext{
${ }^{15}$ Apoyándose en Jacques Derrida y Jacques Lacan, Geoffrey H. Hartman conjetura la existencia de un correlativo a nivel lingüístico de la "fase del espejo", en que el sujeto sería capturado por el nombre que se le otorga (100-4). No creo aventurado sugerir que el apelativo "Mascarita"desencadena en Zuratas una voluntad de enmascaramiento que será extrapolada a la ficción imaginada por el novelista a partir del destino del mestizo peruano enmascarado de judío.

${ }^{16}$ No es esta la primera oportunidad en que Vargas Llosa simboliza la dualidad de un personaje mediante un lunar que le marca la mitad del rostro. Recordemos el caso de Justo, el protagonista del relato "El desafío", recogido en Los jefes (1959), uno de los primeros textos del autor.

${ }^{17}$ Para el tema del barroco remito a: Roberto González Echevarría, Celestina’s Brood...; Mabel Moraña, 259-278; John Beverley, 109-127. El carácter "jánico” que Moraña atribuye al barroco calza bien con la duplicidad de "Mascarita", la cual, a su vez, se potencia en el acierto rotundo de la novela al emplear la fotografía (120-124), medio híbrido por excelencia, como vehículo para el retorno de Zuratas (cf. nota 4).
} 
Es interesante que un texto que se apoya sobre binarismos tradicionales en la construcción de la identidad hispanoamericana culmine con una hibridación generalizada: los turistas que inundan Florencia cada veranos son como un río amazónico (225); los zancudos, animales totémicos y ángeles protectores de Leonardos, Cellinis, Botticellis, Filippos Lippis, Fray Angélicos (225); la prosa de Machiavelli ostenta selváticos ritornellos (228). Frente a la Chiesa de San Lorenzo, un conjunto de “incas” que toca música peruana resulta ser un grupo conformado por dos bolivianos y dos portugueses que interpretan una mezcla de fados y carnavalitos cruceños (227-228). La misma prosa castellana incorpora vocablos italianos: los zanzare de Firenze, la gelateria donde el novelista no puede escribir, la chiusura estivale de la galería donde atendía una muchacha que parte a veranear en Ancona con sus genitori, y que tiene un fidanzato.

Puede que los Machiguengas existan en los márgenes internos producidos por los flujos derivados de los intercambios económicos y culturales del período de globalización en que vivimos -al que alude claramente el final de la novela que vengo mencionandopero la exposición fotográfica en Florencia revela un auditorio dispuesto a "consumir" imágenes de "especímenes étnicos” y reafirma la tradicional performatividad colonialista que se inscribe y manifiesta en la agresión -e intervención- implícita que hay en contemplar/controlar al nativo en su propio hábitat. Las fotografías de los machiguengas se incorporarán, así, al repertorio de imágenes y relatos inconexos que nutren el paisaje mediático del tardocapitalismo (Appadurai). Ante ellas, sin embargo, cabe que recordemos que el silencio de la fotografía metonímicamente nos conduce al silencio del nativo que gravita en el inconsciente neocolonial de El hablador. Desde allí surge la necesidad de suturar la fractura que proclama su no integración al estado-nación así como la necesidad de emplearlo como un fetiche en la batalla, nada simbólica, que libran las tecnologías de la representación.

\section{Bibliografía}

Acosta Cruz, María Isabel. "Writer Speaker? Speaker-Writer? Narrative and Cultural Intervention in Mario Vargas Llosa's El hablador”. Inti 29-30 (1989): 133-45.

Anderson, Benedict. The Spectre of Comparisons: Nationalism, Southeast Asia, and the World. London: Verso, 1998.

Appadurai, Arjun. Modernity at Large. Cultural Dimensions of Globalization. Minneapolis: University of Minnesota Press, 1996.

Aumont, Jacques. El ojo interminable: cine y pintura. Barcelona: Paidós,1997.

Barthes, Roland. "El mensaje fotografico”. Lo obvio y lo obtuso. Imágenes, gestos, voces. Barcelona: Paidós, 1986. 11-27.

La cámara lúcida. Nota sobre la fotografía. Barcelona: Paidós, 1997.

Batchen, Geoffrey. Burning with Desire. The Conception of Photography. Cambridge: MIT Press, 1997.

Baudrillard, Jean. “The Art of Disappearance”. Jean Baudrillard, Art and Artefact. Nicholas Zurbrugg, ed. London: Thousand Oaks/New Dehli: Sage Publications, 1997. 28-31. 
Beltrán Almería, Luis. Palabras transparentes. La configuración del discurso del personaje en la novela. Madrid: Cátedra, 1992.

Benjamin, Walter. Illuminations. New York: Harcourt, Brace \& World, 1968. “El narrador”. Revista de Occidente 129 (1973): 301-32.

"Pequeña historia de la fotografía”. Discursos interrumpidos I. Buenos Aires: Taurus, 1985.

Berger, John. About Looking. New York: Pantheon Books, 1980.

Beverley, John. Una modernidad obsoleta: estudios sobre el barroco. Los Teques: Fondo Editorial A.L.E.M., 1997.

Bhabha, Homi. The Location of Culture. London/New York: Routledge, 2000.

Boland, Roy C. "Sadomasochisme, homosexualité et changement d'identité: les consequences de la castration dans trois romans de Vargas Llosa”. Mario Vargas Llosa: Cahier. Albert Bensoussan, ed. Paris: Editions de l’Herne, 2003. 266-271.

Booker, M. Keith. Vargas Llosa Among the Postmodernists. Gainesville: University Press of Florida, 1994.

Bourdieu, Pierre et al. Photography. A Middle-Brow Art. Stanford: Stanford University Press, 1990.

Calabrese, Elisa. “El hablador de Vargas Llosa o la imposibilidad de la utopía”. Discurso 10/2 (1993): 53-62.

Carullo, Sylvia G. “Dialéctica ‘occidentalización-violencia’ en El hablador”. Texto Crítico 3 (1996): 47-56.

Castro-Klaren, Sara. Understanding Mario Vargas Llosa. Columbia: University of South Carolina Press, 1990.

"Monuments and Scribes: El hablador Addresses Ethnography”. Structures of Power: Essay on Twentieth-Century Spanish-American Fiction. Therry J. Peavler y Peter Standish, eds. Albany: Strate University of New York Press, 1996. 41-57.

Chow, Rey. “Where Have All the Natives Gone?” Contemporary Postcolonial Theory. A Reader. Padmini Mongia, ed. London/New York/Sidney, Auckland: Arnold, 1996. 122-146.

Cohen, Jeffrey Jerome. "Monster Culture (Seven Theses)". Monster Theory. Jeffrey Jerome Cohen, ed. Minneapolis/London: University of Minnesota Press, 1996. 3-25.

Culler, Jonathan. “Anderson and the Novel”. Diacritics 29/4 (1999): 20-39.

Derrida, Jacques. “The Tower of Babel”. Difference in Translation. Joseph F. Graham, ed. Ithaca: Cornell University Press, 1985. 165-248.

y Bernard Stiegler. Echographies of television: filmed interviews. Cambridge, UK: Polity Press/Malden, MA: Blackwell Publishers, 2002.

Dubrovsky, Serge. Autobiographiques. De Corneille à Sartre. Paris: PUF, 1988.

Dunkerley, James. “Mario Vargas Llosa: Parables and Deceits”. New Left Review 162 (1987): 118-119.

Edgar, Andrew and Peter Sedgwick eds. Cultural Theory. The Key Concepts. London/ New York: Routledge, 2002.

Elkins de Snell, Betty. Cuentos folklóricos de los machiguenga.Yarinacocha: Instituto Lingüístico de Verano, 1979.

Ellis, John. Visible Fictions: Cinema, Television, Video. London: Routledge, 1982. 
Espinosa Medrano, Juan de. Apologético.Caracas: Biblioteca Ayacucho, 1982.

Fackenheim, Emil L. What is Judaism? An Interpretation for the Present Age. Syracuse: Syracuse University Press, 1999.

Fludernik Monika. The Fiction of Language and the Language of Fiction. The Linguistic Representation of Speech and Consciousness. London/New York: Routledge, 1993.

Foucault, Michel. Tecnologías del yo. Barcelona: Paidós, 1990.

Los anormales. Curso en el Collège de France (1974-1975). Buenos Aires: Fondo de Cultura Económica, 2000.

Franco, Jean. The Decline and Fall of the Lettered City: Latin America in the Cold War. Cambridge, MA: Harvard University Press, 2002.

Franco, Sergio R. Reseña a El lenguaje de la pasión, de Mario Vargas Llosa. Revista de Crítica Literaria Latinoamericana 56 (2002): 273-76.

Gazzolo, Ana Maria. "El narrador como personaje”. Mario Vargas Llosa: el fuego de la literatura. Néstor Tenorio Requejo, ed. Lima: Arteidea Editores, 2001. 277-80.

González, Eduardo. The Monstered Self: Narratives of Death and Performance in Latin American Fiction. Durham/London: Duke University Press, 1992.

Goodman, Nelson. Los lenguajes del arte. Aproximación a la teoría de los símbolos. Barcelona: Seix Barral, 1976.

González Echevarría, Roberto. Celestina’s Brood. Continuities of the Baroque in Spanish and Latin American Literature. Durham: Duke University Press, 1993.

Myth and Archive. A Theory of Latin American Narrative. Durham/London: Duke University Press, 1998.

Hamburger, Käte. La lógica de la literatura. Madrid: Visor, 1995.

Hartman, Geoffrey H. Saving the Text. Literature/Derrida/Philosophy. Baltimore/London: The Johns Hopkins University, 1981.

Hutcheon, Linda. The Politics of Postmodernism. London/New York: Routledge, 1990.

Irvine, Mark. "La trampa lingüística de identidad en El hablador ¿Otro mundo simbólico?” Mario Vargas Llosa. Escritor, ensayista, ciudadano y político. Encuentro Internacional Pau-Tarbes (Francia), del 23 al 26 de Octubre del 2001. Roland Forgues, ed. Lima: Librería Editorial Minerva, 2001. 465-78.

Jameson, Fredric. "De la sustitución de importaciones literarias y culturales en el Tercer Mundo: el caso del testimonio”. Revista de Crítica Literaria Latinoamericana 36 (1991): 117-132. Signatures of the Visible. London/New York: Routledge, 1992. Postmodernism, or, The Cultural Logic of Late Capitalism. Durham: Duke University Press, 2001.

Jáuregui, Carlos A. y Juan Pablo Davobe, eds. Heterotropías: narrativas de identidad y alteridad latinoamericana. Pittsburgh: IILI-Biblioteca de América, 2003.

Joset, Jacques. Historias cruzadas de novelas hispanoamericanas: Juan Rulfo, Alejo Carpentier, Mario Vargas Llosa, Carlos Fuentes, Gabriel García Márquez, José Donoso. Frankfurt am Main:Vervuert/Madrid: Iberoamericana, 1995.

Kerr, Lucille. Reclaiming the Author. Figures and Fictions from Spanish America. Durham/London: Duke University Press, 1992. 
Klengel, Susanne. "Maira und El hablador: die strukturale un die 'postmoderne' Imagination”. Das Literarische Werk von MarioVargas Llosa. José Morales Saravia, ed. Frakfurt am Main: Vervuert, 2000. 259-82.

Klüppelholz, Heinz. "Le trucage scriptural de l'oralité dans L' home qui parle”. Mario Vargas Llosa: Cahier. Albert Bensoussan, ed. Paris: Editions de l’Herne, 2003. 28189.

Kristal, Efraín. Temptation of the Word: the Novels of Mario Vargas Llosa. Nashville: Vanderbilt University Press, 1998.

Masoliver, Juan Antonio. "El hablador se cansa: retroceso y crisis en Vargas Llosa". Mario Vargas Llosa: el fuego de la literatura. Néstor Tenorio Requejo, ed. Lima: Arteidea Editores, 2001. 273-77.

Mayer, Enrique. "Perú in Deep Trouble: Mario Vargas Llosa's 'inquest in the Andes' Reexamined”. Rereading Cultural Anthropology. George E. Marcus, ed. Durham: Duke University Press, 1992. 181-219.

Millington, Mark I. “Insiders and Outsiders: Cultural Encounter in Vargas Llosa’s La casa verde and El hablador". Forum For Modern Language Studies 2 (1995): 165-76.

Mitcham, Carl y Timothy Casey. "Toward an Archeology of the Philosophy of Technology and Relations with Imaginative Literature”. Literature and Technology. Mark L. Greenberg y Lance Schachterle, eds. Bethlehem: Leigh University Press, 1992. 3165.

Mitchell, W.J T. “Representation”. Critical Terms for Literary Study. Frank Lentricchia y Thomas McLaughlin, eds. Chicago/London: The University of Chicago Press, 1990. 11-22.

Moraña, Mabel. Viaje al silencio. Exploraciones del discurso barroco. México: Facultad de Filosofia y Letras de la Universidad Nacional Autónoma de México, 1998.

Nalbantiam, Suzanne. Aesthetic Autobiography: From Life to Art in Marcel Proust, James Joyce, Virginia Woolf, and Anaïs Nin. New York: St.Martin’s Press, 1994.

Newmark, Julianne. "Language, absence, and Narrative Impossibility in Mario Vargas Llosa’s El hablador”. Latin American Literary Review 61 (2003): 5-22.

O’Bryan-Knight, Jean. The Story of the Storyteller: La tía Julia y el escribidor, Historia de Mayta, and El hablador by Mario Vargas Llosa. Amsterdam/Atlanta: Rodopi, 1995.

Ong, Walter. Orality and Literacy. The Technologizing of the Word. London/New York: Methuen, 1982.

O’Sullivan, Tim et. al. Conceptos clave en comunicación y estudios culturales. Buenos Aires: Amorrortu Editores, 1997.

Penzkofer, Gerhard. "Fremde und eigene Geschichten. Interkulturalität in El hablador von Mario Vargas Llosa”. Das Literarische Werk von Mario Vargas Llosa. José Morales Saravia, ed. Frakfurt am Main: Vervuert, 2000. 211-32.

Rivas, José Andrés. “El hablador: Metáfora de una autobiografía nostálgica”. Antipodas 1 (1988): 190-200.

Sá, Lucía. “Perverse Tribute: Mario Vargas Llosa’s El Hablador and its Machiguenga Sources”. Tesserae: Journal of Iberian and Latin American Studies 4/2 (1998): 145164. 
Poster, Mark. The Mode of Information: Poststructuralism and Social Context. Chicago: University of Chicago Press, 1990.

Scott, Clive. The Spoken Image. Photography and Language. London: Reaktion Books, 1999.

Snook, Margaret L. "Reading and Writing for Meaning: Narrative and Biography in El hablador”. Mester 20/1 (1991): 63-71.

Sommer, Doris. “About-Face: The Talker Turns”. Boundary 2 (1996): 91-133.

Sontag, Susan. On Photography. New York: Farrar, Straus y Giroux, 1977.

Tagg, John. The Burden of Representation: Essays on Photographies and Histories. London: MacMillan Education, 1988.

Vargas Llosa, Mario. Conversación en la catedral. Barcelona: Seix Barral, 1969. Los jefes. Barcelona: Barral Editores, 1972.

La orgía perpetua. Flaubert y Madame Bovary. Madrid: Taurus Ediciones, 1975. El hablador. Barcelona: Seix Barral, 1987.

“El Lunarejo en Asturias”. Contra viento y marea III (1964-1988). Lima: Peisa, 1990. 356-61.

Volek, Emil. Literatura hispanoamericana ente la modernidad y la posmodernidad. Santafé de Bogotá: Universidad Nacional de Colombia, 1994.

Voloshinov. V. N. Le marxisme et la philosophie du langage. Paris: Editions de Minuit, 1977.

Westphalen, Yolanda. “La Mirada de Zavalita hoy: ¿en qué momento se jodió el Perú?” Mario Vargas Llosa. Escritor, ensayista, ciudadano y político. Encuentro Internacional Pau-Tarbes (Francia), del 23 al 26 de Octubre del 2001. Roland Forgues, ed. Lima: Librería Editorial Minerva, 2001. 341-68.

Williams, Raymond L. Vargas Llosa: otra historia de un deicidio. México: Taurus, Universidad Nacional Autónoma de México.

Zavala, Iris. "Representing the Colonial Subject”. 1492-1992: Re/Discovering Colonial Writing. René Jara y Nicholas Spadaccini, eds. Minneapolis/Oxford: University of Minnesota Press, 1989. 323-348.

Zurbrugg, Nicholas, ed. Jean Baudrillard, Art and Artefact. London: Thousand Oaks/ New Dehli: Sage Publications, 1997. 